\title{
Certification of the Equipment for Carriage of Perishable Foodstuffs - Procedure for Measuring the Coefficient of Heat Transfer $K$ of the Insulated Transport Body
}

\author{
Goran PEJIĆ, Tomislav ŠKREBLIN, Janko PRESEČKI
}

\begin{abstract}
The paper presents conditions and procedures for certification of transport equipment regulated by the ATP Agreement. A complete procedure for measuring the overall coefficient of heat transfer $K$ of the insulated transport body is explained in detail. Presented is the arrangement for test procedure with a description of equipment used for measurement of coefficient $K$ in all stages of the procedure - from the testing preparation to the measurement data analysis and calculation of coefficient $K$. Given is an overview of the achieved results of measurement and the prepared final documents on certification of tested insulated transport body of mechanically refrigerated equipment.
\end{abstract}

Keywords: ATP Agreement; ATP certificate; carriage of perishable foodstuffs; Center for Vehicles of Croatia; certification of transport equipment; coefficient of heat transfer $K$; insulated testing chamber

\section{INTRODUCTION}

The ATP Agreement, formally, the Agreement on the International Carriage of Perishable Foodstuffs and on the Special Equipment to be used for such Carriage (ATP) establishes standards for the international transport of perishable foodstuffs between the states that ratify the treaty [1]. A number of countries, including Croatia, have also adopted (or are seeking to adopt) the provisions of the ATP Agreement as the basis for their national legislation relating to the transport of perishable foodstuffs. The ATP Agreement prescribes definitions and standards for special equipment for the carriage of perishable foodstuffs. For special transport equipment to be classified as "insulated", "refrigerated", "mechanically refrigerated" or "heated" the equipment has to undergo the prescribed procedure for testing and certification [2]. Such tests can only be performed by the approved testing stations and the certificates can be issued either by the competent authority of the Contracting State or by its officially authorized body. In Croatia, the Center for Vehicles of Croatia (CVC) has the function of the "approved testing station" for the prescribed testing, inspection and checking of the special transport equipment, as well as the function of the "officially authorized body" for issuing of certificates of compliance and classification of the tested and certified transport equipment [2].

Checking for compliance of the special transport equipment with the standards prescribed in the ATP Agreement (Annex 1, Appendix 1) shall be made: (a) before equipment enters into service, (b) periodically, at least once every six years, and (c) whenever required by the competent authority of the Contracting State. Except in the cases provided for in sections 5 and 6 of the Appendix 2 to the Annex 1 of the ATP Agreement, the checks shall be made at a testing station designated or approved by the competent authority of the country in which the equipment is registered or recorded, unless, in the case of the check referred to in (a) above, a check has already been made on the equipment itself or on its prototype in a testing station designated or approved by the competent authority of the country in which the equipment was manufactured.

The paper presents the procedures for certification of newly built mechanically refrigerated equipment for the carriage of perishable foodstuffs. Checking for compliance with the standards was conducted according to the prescribed procedure for measurement of the overall coefficient of heat transfer $K$ of the insulated transport body and the use of required technical data (obtained from a valid certificate of compliance) of a mechanical cooling appliance. The measurement of coefficient $K$ has been conducted in a modern fullyequipped newly built insulated testing chamber of the Center for Vehicles of Croatia in Ozalj. In order to meet all of the terms for testing of transport equipment, during the last five years - apart from the construction of the insulated testing chamber and the professional staff training - the CVC has developed its own, comprehensive system for measuring and control inside and outside the insulated transport body. The complete procedure of testing and certification of transport equipment includes a testing preparation phase, a phase of measurement and recording of results of measurement of coefficient $K$, a phase of data analysis and ascertaining of final measurement results along with production of test report, and a final phase of preparation and issuance of certificates, certification plates and classification labels for the prescribed designation of tested/certified transport equipment.

\section{MECHANICALLY REFRIGERATED EQUIPMENT}

Mechanically refrigerated equipment for the carriage of perishable foodstuffs is insulated equipment either fitted with its own refrigerating appliance, or served jointly with other units of transport equipment by such an appliance, (fitted with either a mechanical compressor, or an "absorption" device, etc.). The appliance shall be capable, with a mean outside temperature of $+30{ }^{\circ} \mathrm{C}$, of lowering the temperature $T_{\mathrm{i}}$ inside the empty body to, and thereafter maintaining it continuously in the following manner: 
1) In the case of classes $\mathrm{A}, \mathrm{B}$ and $\mathrm{C}$, any desired practically constant inside temperature $T_{\mathrm{i}}$ in conformity with the standards defined below for the three classes:

- Class A. Mechanically refrigerated equipment fitted with a refrigerating appliance so that $T_{\mathrm{i}}$ may be chosen between $+12{ }^{\circ} \mathrm{C}$ and $0{ }^{\circ} \mathrm{C}$ inclusive;

- Class B. Mechanically refrigerated equipment fitted with a refrigerating appliance so that $T_{\mathrm{i}}$ may be chosen between $+12{ }^{\circ} \mathrm{C}$ and $-10{ }^{\circ} \mathrm{C}$ inclusive;

Class C. Mechanically refrigerated equipment fitted with a refrigerating appliance so that $T_{\mathrm{i}}$ may be chosen between $+12{ }^{\circ} \mathrm{C}$ and $-20{ }^{\circ} \mathrm{C}$ inclusive.

2) In the case of classes $\mathrm{D}, \mathrm{E}$ and $\mathrm{F}$ a fixed practically constant inside temperature $T_{\mathrm{i}}$ in conformity with the standards defined below for the three classes:

- Class D. Mechanically refrigerated equipment fitted with a refrigerating appliance so that $T_{\mathrm{i}}$ is equal to or less than $0{ }^{\circ} \mathrm{C}$;

- Class E. Mechanically refrigerated equipment fitted with a refrigerating appliance so that $T_{\mathrm{i}}$ is equal to or less than $-10^{\circ} \mathrm{C}$;

- Class F. Mechanically refrigerated equipment fitted with a refrigerating appliance so that $T_{\mathrm{i}}$ is equal to or less than $-20^{\circ} \mathrm{C}$.

The overall coefficient of heat transfer $K$ (hereinafter referred to as coefficient $K$ ) of equipment of classes $\mathrm{B}, \mathrm{C}$, $\mathrm{E}$ and $\mathrm{F}$ shall in every case be equal to or less than 0.40 $\mathrm{W} / \mathrm{m}^{2} \mathrm{~K}$.

For issuance of a certificate for mechanically refrigerated equipment, in compliance with the Appendix 3 to the Annex 1 of the ATP Agreement, a coefficient $K$ of the insulated transport body shall be measured according to the paragraph 2 of the Appendix 2 to the Annex 1, as well as the effective refrigerating capacity $W_{0}$ of a mechanical cooling appliance according to the paragraph 4 of the Appendix 2 to the Annex 1 of the ATP Agreement.

This paper explains in detail the complete procedure of measurement of coefficient $K$ of the insulated transport body. Values of the effective refrigerating capacity $\mathrm{W}_{0}$ of a mechanical cooling appliance as well as its other technical data were obtained from a certificate issued by the authorized body of the country in which the appliance was manufactured.

\section{MEASUREMENT OF COEFFICIENT $K$ OF THE INSULATED TRANSPORT BODY \\ 3.1 Introductory Remarks}

In conformity with the provisions of section 2 of the Appendix 2 to the Annex 1 of the ATP Agreement, the coefficient $K$ shall be measured in continuous operation either by the internal cooling method or by the internal heating method. In either case, the empty insulated transport body shall be placed in an insulated testing chamber. In our case, the coefficient $K$ is measured using the internal heating method, meaning that during the measurement of coefficient $K$ of the insulated transport body a mean temperature of $+32.5{ }^{\circ} \mathrm{C}$ is maintained inside the body by using the heating appliance. Outside the insulated transport body, placed within the insulated testing chamber, mean temperature is maintained at +7.5 ${ }^{\circ} \mathrm{C}$ by use of its cooling/heating system.

\subsection{Equipment Used for Measurement of Coefficient $K$}

In the procedure of measurement of coefficient $K$ of the insulated transport body the following equipment was used:

- $\quad$ an insulated testing chamber,

a cooling/heating system of the insulated testing chamber,

a control room,

a system for measuring and control inside and outside the insulated transport body,

a thermovision camera FLIR E6,

a digital anemometer DA40V,

a central information system of the CVC,

a digital photo-camera,

a length gauge (10-meter steel meter).

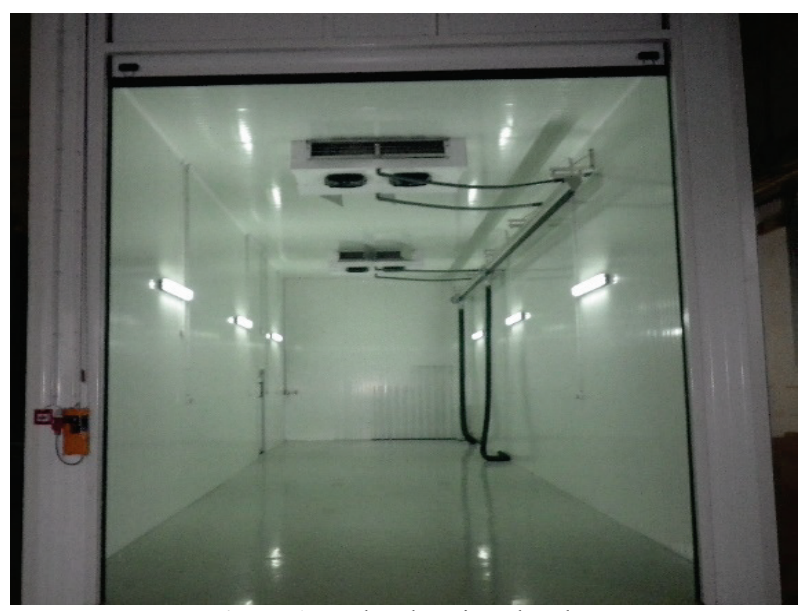

Figure 1 Insulated testing chamber

The insulated testing chamber $(16.5 \times 5.0 \times 5.0 \mathrm{~m})$ (Fig. 1) is situated inside a "Montaža" factory hall of Flammifer d.o.o company in Ozalj and it is constructed of $80 \mathrm{~mm}$ thick ISOMEC refrigeration panel.

The cooling/heating system of the insulated testing chamber (cooling capacity of $25 \mathrm{~kW}$; heating capacity of $18 \mathrm{~kW}$ ) is composed of:

- an air-cooled condensing unit DORIN, type H151CC $\left(t_{0} / t_{\mathrm{k}}=-5^{\circ} \mathrm{C} / 45^{\circ} \mathrm{C}\right)$,

- two ceiling-mounted dynamic unit coolers LU-VE, type $\mathrm{CD} 45 \mathrm{H} 8104 \mathrm{E} 4\left(t_{0}=-5{ }^{\circ} \mathrm{C}\right)$ fitted with electric defrost heaters and with additional heaters for heating the insulated testing chamber,

- a condenser LU-VE, type SAV 5N 4332 V7VN $\left(t_{\mathrm{k}}=\right.$ $+45^{\circ} \mathrm{C}$ ),

- a wall-mounted electric control unit REGIN Corrigo E15.

The insulated testing chamber with its cooling/heating system reliably maintains the heating at any desired mean temperature inside the chamber between $0{ }^{\circ} \mathrm{C}$ and $+30{ }^{\circ} \mathrm{C}$ with a tolerance of $0.2{ }^{\circ} \mathrm{C}$ during the calculation period (of measurement of coefficient $K$ ) which cannot be shorter than six hours (for the 12 points of measurement around the insulated transport body) provided that during the same time period the maximum difference between the temperatures at the warmest and at the coldest of the 12 measurement points does not exceed $2{ }^{\circ} \mathrm{C}$. 
The control room $(5.5 \times 3.0 \times 2.7 \mathrm{~m})$ is equipped with a wall-mounted electric control unit for the cooling/heating system of the insulated testing chamber (Fig. 2) and is a part of the system for measuring and control inside and outside the insulated transport body (Fig. 3).

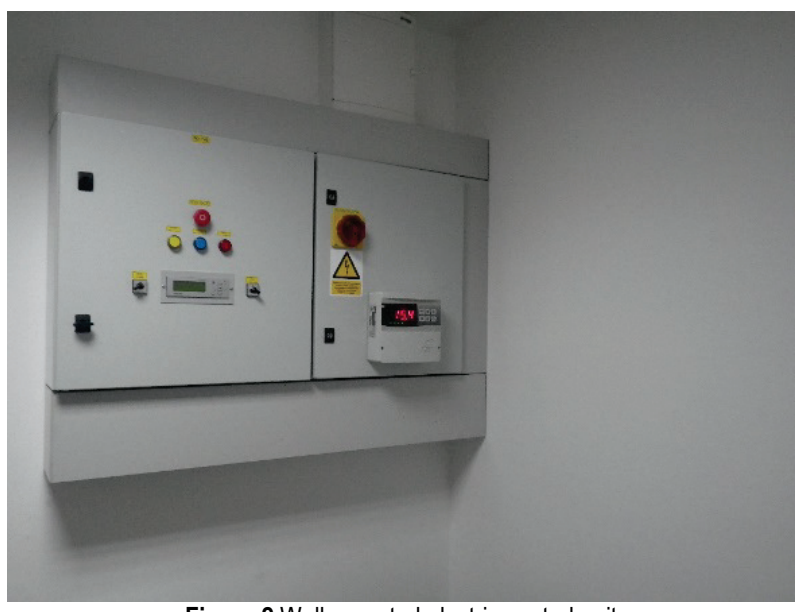

Figure 2 Wall-mounted electric control unit

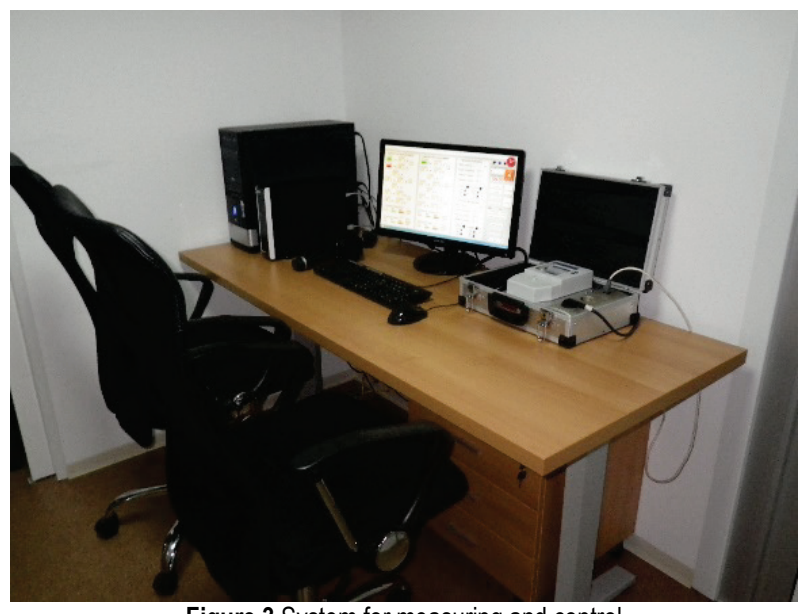

Figure 3 System for measuring and control

During the testing of the insulated transport body an expert (experts) of the CVC spends most of the time in the control room monitoring and directing the whole system (and the procedure) for measurement of coefficient $K$.

The system for measuring and control inside and outside the insulated transport body is composed of: a personal computer (PC), microcontroller subsystem, energy gauge, heating appliances, fans, digital thermometers (T) and Ethernet cables (Fig. 4).

The central element of the system for measuring and control inside and outside the insulated transport body is a microcontroller subsystem to which digital thermometers are interconnected serially by Ethernet cables (12 inside and 12 outside the insulated transport body). This controller also regulates the heating inside the insulated transport body. Each temperature measurement sensor has a unique address on the grid. The heating control signal is connected by an Ethernet cable to heating appliances maximum of 4 heating appliances serially interconnected by Ethernet cables. Each heating appliance has a maximum power of $2 \mathrm{~kW}$ (two heaters of $1 \mathrm{~kW}$ each); and lower power can be achieved with PWM regulation.

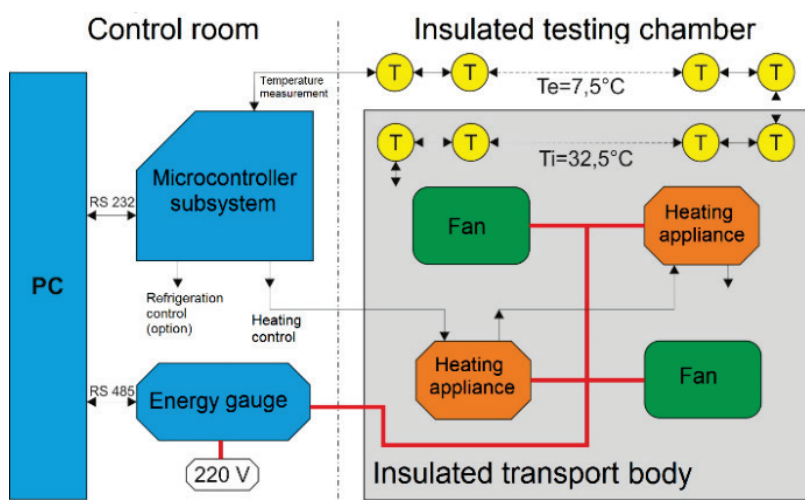

Figure 4 System for measuring and control inside and outside the insulated transport body

The energy gauge is an electronically programmable, one phase smart meter RIZ EBM 108-C1, which measures the dissipation of all of the loads inside the insulated transport body, and all of the heat introduced into the insulated transport body. Loads are the regulated heaters and fans which ensure the prescribed air circulation and the reduction of temperature gradients inside the insulated transport body. Every minute, from the electronic smart meter via RS485 communication, are read data regarding the cumulative sum of energy introduced into the insulated transport body.

Data from the digital thermometers are read every second via RS232 communication. Thermometers have a quick response time and a negligible dissipation in order to enable the regulation of temperature with the smallest possible spatial gradient as well as the smallest possible tolerance of mean temperature from a given value (in this case the prescribed mean temperature inside the insulated transport body is $+32.5{ }^{\circ} \mathrm{C}$ and the prescribed mean temperature outside the insulated transport body is +7.5 $\left.{ }^{\circ} \mathrm{C}\right)$.

A graphical user interface of the PC presents in realtime all the parameters and measured values. It also allows a user to interactively calculate, during the measurement, various statistical parameters for estimation of the final results as well as for the modification of parameters for the regulation of temperature.

Results of the measurement are stored on a disk in a data file of a format appropriate for further analyses in the Microsoft Office Excel program. In this particular case, data that are saved in the data file are the identification number of the insulated transport body, the positioning and the identification number of each of the temperature measurement sensors as well as the time of measurement, the energy introduced into the insulated transport body, and the mean temperature in each of the points of measurement inside and outside of the insulated transport body - all measured in one-minute intervals.

Digital anemometer DA40V is used for the measurement of the speed of the air flow inside the insulated testing chamber.

Thermovision camera FLIR E6 is used for screening and recording of the areas of the insulated transport body which have significantly higher heat transfers (the socalled thermal bridges). The screened and recorded areas of higher heat transfers in further analyses allow the owners of the insulated transport bodies to decide on the potential improvements of the used insulated transport 
bodies or the elimination of the weak (not properly designed) areas when constructing the new insulated transport bodies.

\subsection{Procedure for Measurement of Coefficient $K$ of the Insulated Transport Body \\ 3.3.1 Documentation Verification}

An expert of the Center for Vehicles of Croatia (hereinafter referred to as: CVC expert) verifies the legal and technical documentation of the transport equipment and determines its completeness and authenticity. From the documentation, the CVC expert fills out a Report on the measurement of the overall coefficient of heat transfer $K$ of the insulated transport body for carriage of perishable foodstuffs (hereinafter referred to as: Report) according to the Models No. 1 A and No. 2 A from the Appendix 2 to the Annex 1 of the ATP Agreement.

\subsubsection{Placement of the Insulated Transport Body in the Insulated Testing Chamber}

A driver drives the vehicle with the insulated transport body into the insulated testing chamber, parks it in a place indicated by the instructions of the CVC expert, and opens all the doors on the insulated transport body.

\subsubsection{Verification of the Identification Numbers and Control of the Dimensions of the Insulated Transport Body}

The CVC expert verifies the identification numbers of the vehicle, the insulated transport body and the mechanical cooling appliance and enters all the data into Report. He then checks the condition of the insulating walls, doors, floor, roof, seals and seal seats on the doors of the insulated transport body. He measures the dimensions of the doors, thickness of the sidewalls, floor, roof, as well as the outside and inside dimension of the insulated transport body (the length, width and height) and enters the correct and verified data into Report. During the checking and verification, the CVC expert takes photographs of the particular details.

\subsubsection{Setting Up of the System for Measuring and Control Inside and Outside the Insulated Transport Body}

The CVC expert places 12 digital thermometers (T) into the insulated transport body $100 \mathrm{~mm}$ from the inside walls (Fig. 5) at the following points:

a) the eight inside corners of the insulated transport body,

b) the centers of the four inside faces of the insulated transport body having the largest area.

If the insulated transport body is not parallelepipedic, the 12 points of measurements shall be distributed as satisfactorily as possible with regard to the shape of the insulated transport body. In such case the arrangement of the measuring points is entered in the Report under the heading "Remarks".

Heating appliances and fans are placed and arranged properly inside the insulated transport body (Fig. 5) in such a number to ensure the even heating of the entire area inside the insulated transport body with a mean temperature of $+32.5^{\circ} \mathrm{C}$. All of the heating appliances are serially interconnected by Ethernet cables and then are connected to the microcontroller subsystem for the regulation of temperature. Heating appliances and fans are connected between themselves by extension cords and then connected to the energy gauge.

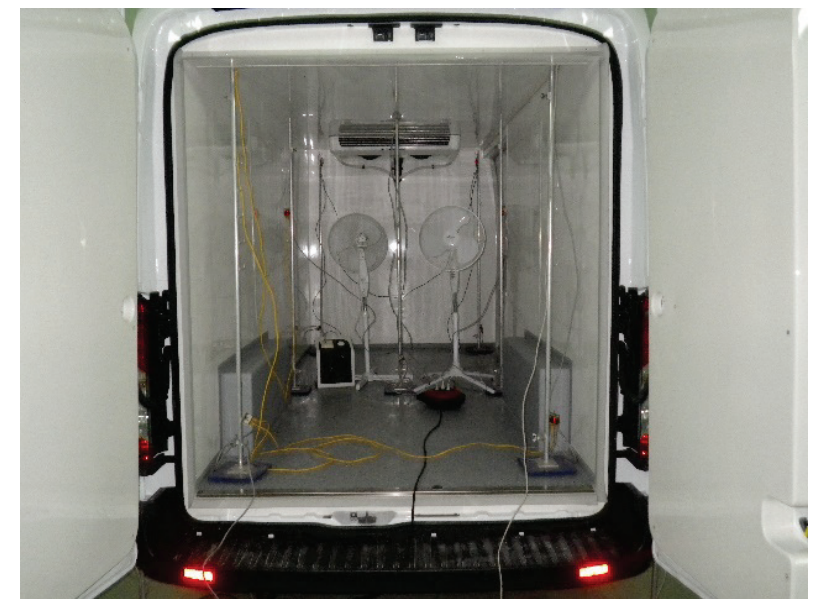

Figure 5 Arrangement of thermometers, heating appliances and fans inside the insulated transport body

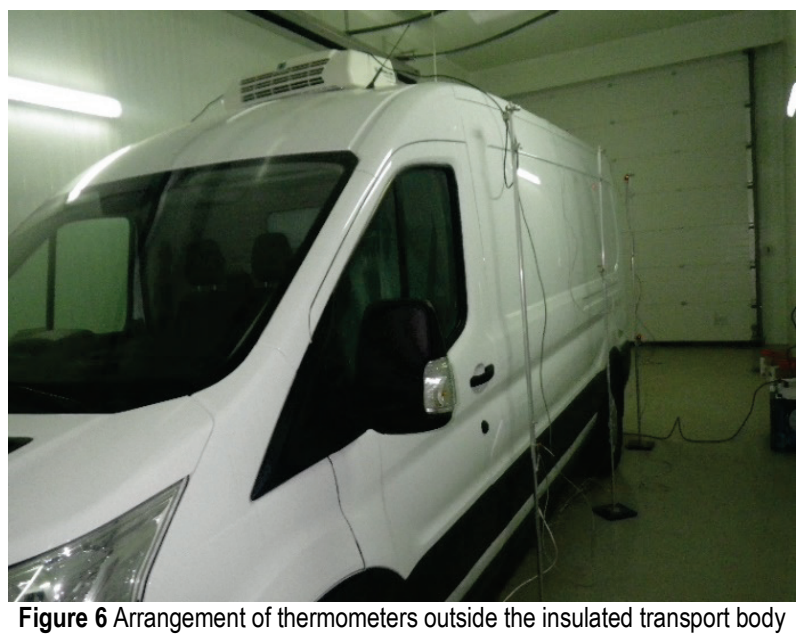

On the outside of the insulated transport body the CVC expert places 12 digital thermometers $100 \mathrm{~mm}$ from the walls (Figs. 6 and 7) at the following points:

a) the eight outside corners of the insulated transport body,

b) the centers of the four outside faces of the insulated transport body having the largest area.

If the insulated transport body is not parallelepipedic, the 12 points of measurements shall be distributed as satisfactorily as possible with regard to the shape of the insulated transport body. In such case the arrangement of the measuring points is entered in the Report under the heading "Remarks".

The CVC expert serially interconnects all the digital thermometers (12 inside and 12 outside) by Ethernet cables and then connects them to the microcontroller subsystem for the measurement of temperature.

When all the equipment is properly assembled and installed, the CVC expert takes photographs of the said equipment inside and outside the insulated transport body and closes all the doors and openings on the insulated transport body in order to ensure the least possible 
exchange of heat between the insulated transport body and the insulated testing chamber.

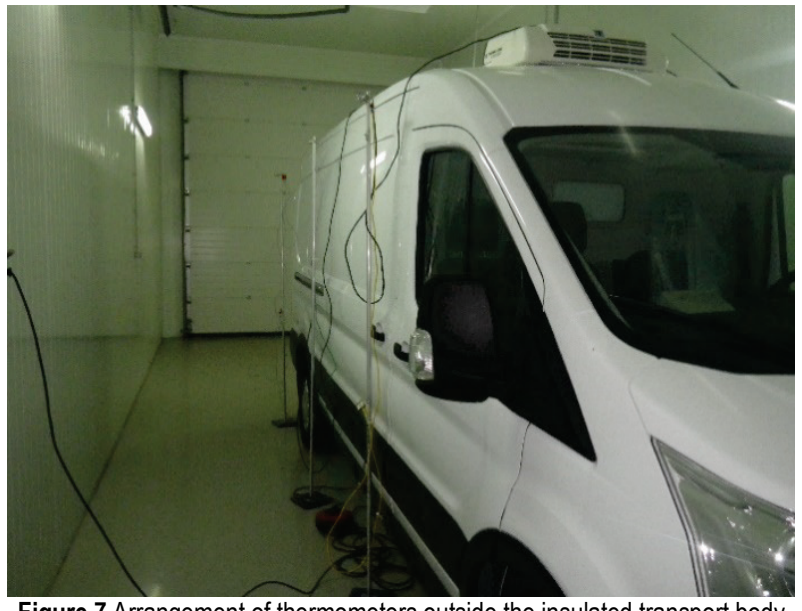

Figure 7 Arrangement of thermometers outside the insulated transport body

\subsubsection{Activation of the System for Measuring and Control Inside and Outside the Insulated Transport Body, and the Cooling/Heating System of the Insulated Testing Chamber}

The CVC expert, working on the PC, enters the identification number of the insulated transport body and activates the measurement of coefficient $K$. He then sets on one of the thermometers placed inside the insulated transport body the control temperature to $+32.5{ }^{\circ} \mathrm{C}$. On the screen of the electric control unit of the cooling/heating system he sets the mean outside temperature of the insulated transport body to $+7.5^{\circ} \mathrm{C}$, and activates the cooling/heating system of the insulated testing chamber. Subsequently, the CVC expert measures the speed of the air flow, using a digital anemometer placed at approximately $100 \mathrm{~mm}$ from the walls of the insulated testing chamber and enters the data into the Report. Afterwards, he closes the side doors of the insulated testing chamber and monitors the whole procedure of further measurement of coefficient $K$ from the control room.

\subsubsection{Adjustment of the Arrangement of Heating Appliances and Fans Inside the Insulated Transport Body, and the Parameters Set Up on the System for Measuring and Control Inside and Outside the Insulated Transport Body}

During the monitoring of the procedure of coefficient $K$ measurement, the CVC expert observes all the parameters and measured values on the PC screen (Figs. 8, 9 and 10) and where necessary makes modifications (adjustments of the arrangement of heating appliances and fans inside the insulated transport body, or selects another control thermometer inside the insulated transport body and sets on it a different control temperature, and on the screen of the electric control unit sets accordingly a different outside temperature of the insulated transport body, etc.).

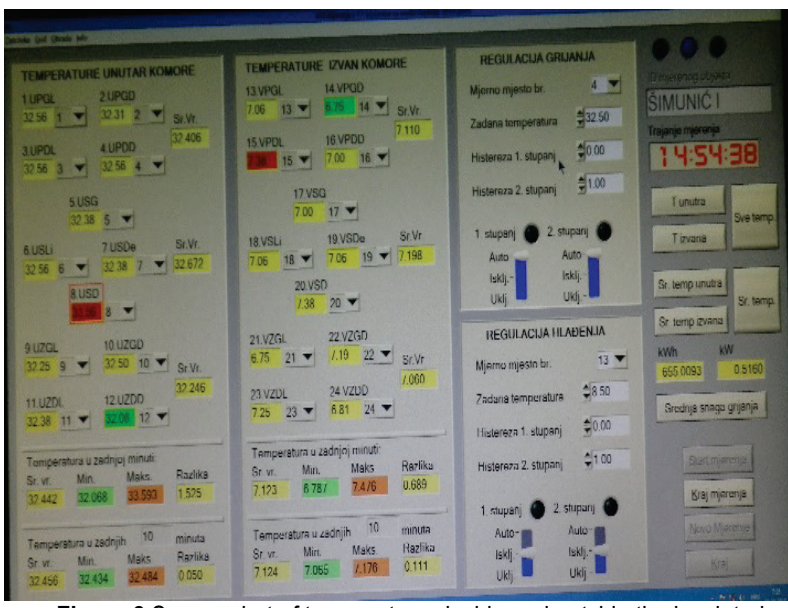

Figure 8 Screen shot of temperatures inside and outside the insulated transport body

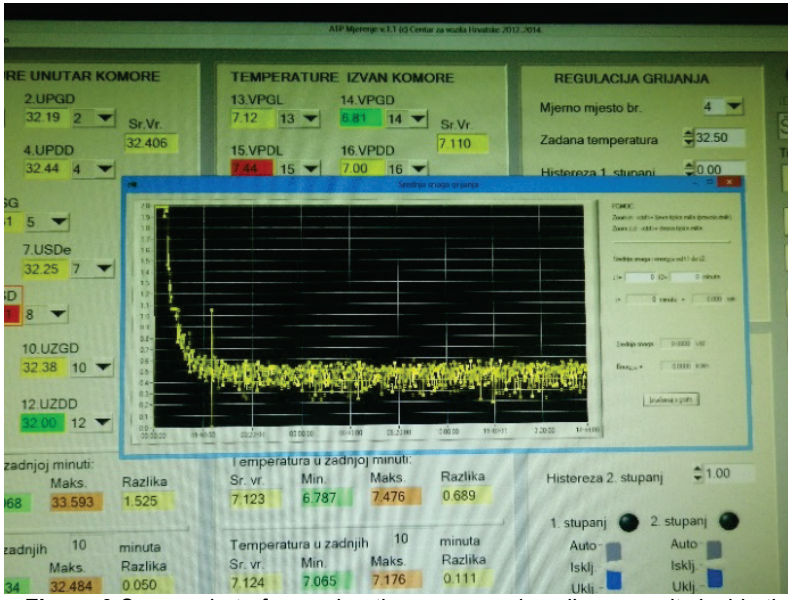

Figure 9 Screen shot of mean heating power and cooling capacity inside the insulated transport body

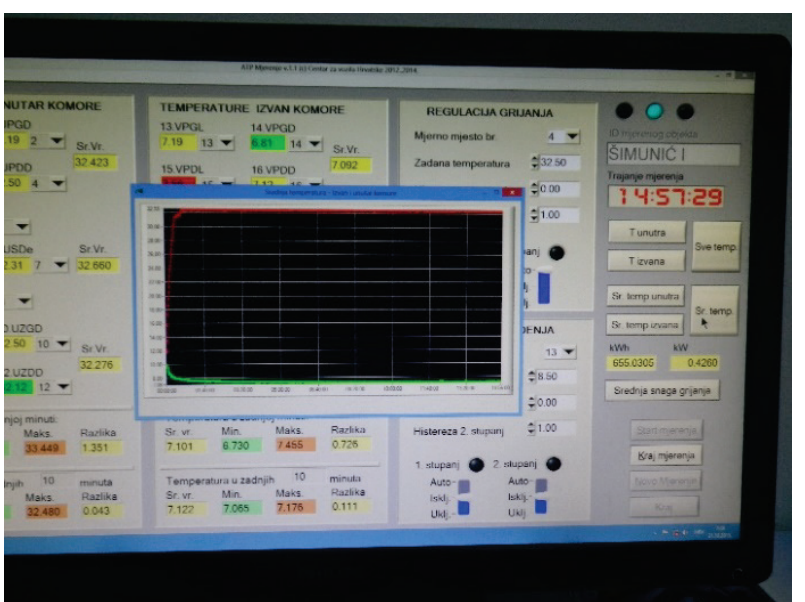

Figure 10 Screen shot of mean temperatures inside and outside the insulated transport body

\subsubsection{Values Used in $K$ Coefficient Calculation}

Values used in $K$ coefficient calculation may be used when the following conditions are achieved/satisfied: - the mean temperature inside the insulated testing chamber is kept uniform and constant at $+7.5^{\circ} \mathrm{C} \pm 0.5^{\circ} \mathrm{C}$; - the mean outside temperature of the insulated transport body is $+7.5^{\circ} \mathrm{C}$ and the mean inside temperature of the insulated transport body is $+32.5{ }^{\circ} \mathrm{C}$, or if a condition is satisfied that the difference between the mean 
inside and mean outside temperature of the insulated transport body is $25^{\circ} \mathrm{C} \pm 2{ }^{\circ} \mathrm{C}$;

- the mean temperature of the walls of the insulated transport body is $+20{ }^{\circ} \mathrm{C} \pm 0.5^{\circ} \mathrm{C}$;

- $\quad$ the maximum difference between any two of the 12 measurement points outside the insulated transport body does not exceed $2{ }^{\circ} \mathrm{C}$.

\subsubsection{Steady State Period}

Values recorded every minute on the PC drive which enable the calculation of all of the required parameters necessary for the calculation of coefficient $K$, are the following:

- the mean inside temperature of the transport body $\left(T_{\mathrm{i}}\right)$; $\left(T_{\mathrm{e}}\right)$;

- the mean difference between temperatures $\Delta T=T_{\mathrm{i}}$ $T_{\mathrm{e}}$;

- the mean temperature of the walls of the insulated transport body $T_{\mathrm{s}}=\left(T_{\mathrm{i}}+T_{\mathrm{e}}\right) / 2$;

- the mean heating power and cooling capacity inside the insulated transport body $W_{1}+W_{2}$; where $W_{1}$ is the power consumed in heat exchangers (heaters) in $\mathrm{W}$, and $W_{2}$ is the power absorbed by fans in $\mathrm{W}$.

The mean inside temperatures and the mean outside temperatures of the insulated transport body, taken over a steady period of not less than 12 hours, shall not vary by more than $\pm 0.3{ }^{\circ} \mathrm{C}$, and these temperatures shall not vary by more than $\pm 1{ }^{\circ} \mathrm{C}$ during the preceding period of 6 hours.

The difference between the mean heating power and cooling capacity inside the insulated transport body measured over two periods of not less than 3 hours - at the start and at the end of the steady state period, and separated by at least 6 hours - shall be less than $3 \%$.

The mean inside and outside temperatures of the insulated transport body during the calculation period of at least 6 hours shall not differ by more than $0.2^{\circ} \mathrm{C}$, and the difference between the temperatures of any 2 of the 12 measurement points outside the insulated transport body shall not exceed $2{ }^{\circ} \mathrm{C}$ during the same period.

\subsubsection{Shutdown of the Measurement Procedure}

After all the conditions specified in paragraph 3.3.8 are satisfied, the CVC expert stops on his PC the procedure of measurement of coefficient $K$, shuts down the power supply to the heating appliances and fans inside the insulated transport body, as well as the power supply to the cooling/heating system of the insulated testing chamber. He then opens the doors on the insulated transport body, removes and sets aside all the equipment used for measuring and control inside and outside the insulated transport body.

\subsubsection{Report Printout and Measurement Data Analysis}

From the measurement data, stored on the PC drive, the CVC expert using the Microsoft Office Excel program calculates all the required parameters, prints out the
Report, and calculates the coefficient $K$. He then stores all of the results from the PC to a USB memory drive.

\subsubsection{Storage of Documents, Photographs and Measurement Data in the Central Information System of the CVC}

The CVC expert scans the Report and all the technical and legal documentation of the transport equipment, and stores them, together with the photographs from the digital photo-camera and the thermovision camera, in the central information system of the CVC under the number issued at the transport equipment testing check-in.

\subsubsection{Printout of Final Documents}

On the basis of the calculated coefficient $K$, the Report and the necessary data from the technical and legal documentation, as well as the values of the effective refrigerating capacity $W_{0}$ and other data that from the mechanical refrigerator certificate, the CVC expert specifies the class of the mechanically refrigerated equipment for carriage of perishable foodstuffs. He then fills out, on the PC, and prints out the certificate of compliance of the transport equipment, in conformity with the paragraph A of the Appendix 3 to the Annex 1 of the ATP Agreement. Afterwards, the CVC expert fills out (on the PC) and prints out the certification label of compliance of the transport equipment, in conformity with the paragraph B of the Appendix 3 to the Annex 1 of the ATP Agreement. Finally, he orders the distinguishing marks that are to be affixed to transport equipment, in conformity with the Appendix 4 to the Annex 1 of the ATP Agreement

\subsubsection{Preparation of Final Documents}

The certificate, verified and signed by the authorized officer of the CVC, together with the certification label and distinguishing marks ( 2 items) is sent by mail or delivered in person to the accredited representative of the owner of the tested mechanically refrigerated equipment for carriage of perishable foodstuffs.

\section{ACHIEVED RESULTS OF MEASUREMENT OF THE TESTED INSULATED TRANSPORT BODY AND PREPARED FINAL DOCUMENTS OF THE MECHANICALLY REFRIGERATED EQUIPMENT FOR CARRIAGE OF PERISHABLE FOODSTUFFS}

The here described procedure was used for certifying the mechanically refrigerated equipment (insulated transport body: manufacturer MKKZ-Termoizolacija, type TIF-60, serial number 082/2015, vehicle Ford Transit VIN mark WF0XXXTTGXFT43591, mechanical refrigerator: manufacturer THERMO KING, type V-200 MAX, serial number BCN1012372). Achieved were, by measurement and calculation, the following final test results:

- $\quad$ the total outside surface area of the insulated transport body $S_{\mathrm{e}}=31.25 \mathrm{~m}^{2}$ 
- $\quad$ the total inside surface area of the insulated transport body $S_{\mathrm{i}}=26.13 \mathrm{~m}^{2}$

- the mean surface area of the insulated transport body $S=28.57 \mathrm{~m}^{2}$

- $\quad$ the mean heating power and cooling capacity inside the insulated transport body from the start until the end of measurement of coefficient $K$ (Fig. 11)

- the mean inside and mean outside temperature of the insulated transport body from the start until the end of measurement of coefficient $K$ (Fig. 12)

- the mean outside temperature of the insulated transport body during the calculation period $T_{\mathrm{e}}=7.108^{\circ} \mathrm{C}$ $\pm 0.06^{\circ} \mathrm{C}$

- the mean inside temperature of the insulated transport body during the calculation period $T_{\mathrm{i}}=32.46{ }^{\circ} \mathrm{C} \pm 0.05$ ${ }^{\circ} \mathrm{C}$

- the mean difference between temperatures $\Delta T=T_{\mathrm{i}}$ $T_{\mathrm{e}}=32.46-7.108=25.35^{\circ} \mathrm{C}$

- the mean heating power and cooling capacity during the period of 190 minutes at the beginning of the steady state period $\mathrm{W}_{01}=447.3 \mathrm{~W}$

- the mean heating power and cooling capacity during the period of 190 minutes at the end of the steady state period $W_{02}=445.1 \mathrm{~W}$

- the difference between the measured mean heating powers and cooling capacity $W_{01}$ and $W_{02}$ of the insulated transport body, which has to be less than $3 \%$ in relation to $W_{01}$, is:

$$
\varepsilon=\frac{\left|W_{01}-W_{2}\right|}{W_{01}} \cdot 100 \%=\frac{|447.3-445.1|}{447.3} \cdot 100 \%=0.49 \% \text {. }
$$

- $\quad$ the duration of the steady state period $t_{\mathrm{p}}=16.6$ hours $\%$

- the duration of the calculation period $t_{\mathrm{r}}=6$ hours - the sum of the mean heating power $\left(W_{1}\right)$ and the mean cooling capacity $\left(W_{2}\right)$ during the calculation period, measured with the joint gauge, is $W_{1}+W_{2}=445.3 \mathrm{~W}$

- the overall coefficient of heat transfer $K$ of the insulated transport body:

$K=\frac{W_{1}+W_{2}}{S \cdot \Delta T}=\frac{445.3}{28.57 \cdot 25.35}=0.614 \mathrm{~W} / \mathrm{m}^{2} \mathrm{~K}$

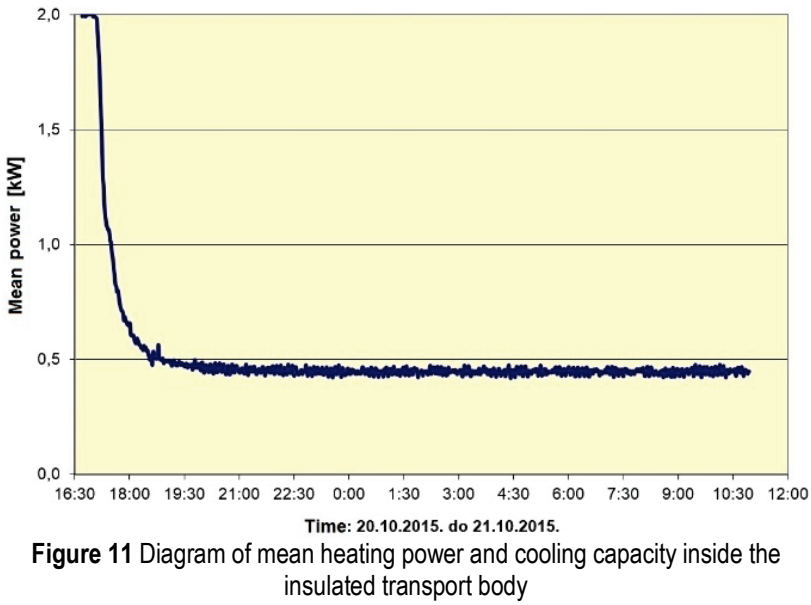

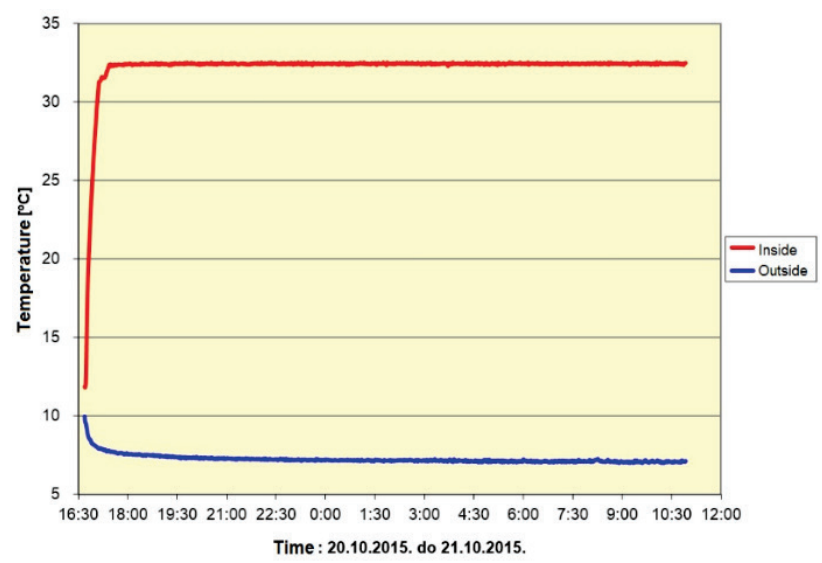

Figure 12 Diagram of mean inside and mean outside temperature of the insulated transport body

Technical data for the mechanical refrigerator V-200 MAX (from the certificate):

- effective refrigerating capacity of a mechanical cooling appliance at the outside temperature of +30

${ }^{\circ} \mathrm{C}$ and the inside temperature of: $0{ }^{\circ} \mathrm{C}, W_{0}=2771 \mathrm{~W}$;

$-10{ }^{\circ} \mathrm{C}, W_{0}=2047 \mathrm{~W} ;-20{ }^{\circ} \mathrm{C}, W_{0}=1456 \mathrm{~W}$

- refrigerant filling: R404A

- $\quad$ serial number: BCN1012372

- $\quad$ year of manufacture: 2015

For the mechanically refrigerated equipment of class A (FNAX) along with the specified characteristics, it is necessary that the mechanical cooling appliance at the outside temperature of $+30{ }^{\circ} \mathrm{C}$ and the inside temperature of $0{ }^{\circ} \mathrm{C}$, where $\Delta T=30-0=30^{\circ} \mathrm{C}$, has the effective refrigerating capacity of:

$W_{0}=1.75 \cdot K \cdot S \cdot \Delta T=1.75 \cdot 0.614 \cdot 28.57 \cdot 30=920.9 \mathrm{~W}$

Given that the fitted mechanical cooling appliance at the specified conditions has the effective refrigerating capacity of $W_{0}=2771 \mathrm{~W}$ which is higher than the required, the mechanically refrigerated equipment in question is assigned to class A (FNAX) valid for the period of six years.

On the basis of measured and calculated values of the insulated transport body and the values from the certificated of the mechanical cooling appliance, the following final documents were prepared and delivered to the owner of the mechanically refrigerated equipment

- the Certificate of compliance of the mechanically refrigerated equipment;

- the Certification label of compliance of the mechanically refrigerated equipment;

- the distinguishing marks of the mechanically refrigerated equipment.

\section{CONCLUSION}

The ATP Agreement specifies, among other things, the classes of the mechanically refrigerated equipment for the carriage of perishable foodstuffs, as well as the standards which a particular class of equipment has to meet in order to be properly used in the international transport. Prescribed are also the provisions relating to the checking of particular class of equipment for compliance 
with standards. This paper presented one of such checking of the mechanically refrigerated equipment for compliance with standards. The procedure of checking for compliance, that is the prescribed procedure for testing and certification can only be performed by the "approved testing stations", listed in the Competent Authorities and Test Stations register of the Working Party on Transport of Perishable Foodstuffs - WP 11 within the UNECE in Geneva. In Croatia, the only such approved testing station is the Center for Vehicles of Croatia. In order for the prescribed procedure for testing and certification of special equipment, as defined by the ATP Agreement, to be performed, it is necessary to have access to a fullyequipped insulated testing chamber, testing equipment (fixed and portable), appropriate system for measuring and control inside and outside the insulated transport body - fitted, for testing purposes, inside the insulated testing chamber, as well as trained professional staff. The Center for Vehicles of Croatia fully meets all of these conditions, and is therefore qualified and officially authorized for the complete performance of various testing, checking, and approval or certification of all types of special equipment for the carriage of perishable foodstuffs - in compliance with the specifications and provisions of the ATP Agreement in force.

\section{REFERENCES}

[1] (2017). ECE/TRANS/271. Agreement on the International Carriage of the Perishable Foodstuffs and on the Special Equipment to be Used for such Carriage (ATP), United Nations Publication, Sales No. E.17.VIII.2, ISBN 978-92-1139160-2

[2] Presečki, J., Pejić, D., \& Ferić, M. (2015). Prijevoz lako pokvarljivih prehrambenih proizvoda u Republici Hrvatskoj - pregled, provjera, ispitivanje i certificiranje transportne opreme. Suvremeni promet, 35(1-2), 41-47.

\section{Contact information:}

Goran PEJIĆ, B.Eng., M.Sc.

Center for Vehicles of Croatia

Capraška ulica 6, 10000 Zagreb, Croatia

e-mail: goran.pejic@cvh.hr

Tomislav ŠKREBLIN, B.Eng

Center for Vehicles of Croatia

Technical Department

Capraška ulica 6, 10000 Zagreb, Croatia

e-mail: tomislav.skreblin@cvh.hr

Janko PRESEČKI, B.Eng.

Center for Vehicles of Croatia

Vehicle Testing Department

Sisačka cesta 39c, 10410 Velika Gorica, Croatia

e-mail: janko.presecki@cvh.hr 